- Original Article

\title{
Mental Health of the People with Hearing Impairment in Korea: $A$ Population-Based Cross-Sectional Study
}

\author{
Hyun-Young Shin ${ }^{1,2}$, Hee-Jin Hwang ${ }^{3, *}$ \\ 'Department of Family Medicine, Myongji Hospital, Seonam University College of Medicine, Goyang, Korea \\ ${ }^{2}$ Department of Medicine, Catholic Kwandong University College of Medicine, Gangneung, Korea \\ ${ }^{3}$ Department of Family Medicine, Institute for Translational and Clinical Research, Catholic Kwandong University International St. Mary's Hospital, \\ Incheon, Korea
}

Background: The prevalence of hearing impairment is increasing and an association between hearing impairment and mental health has been reported. Our study aimed to determine the association between hearing impairment and mental health in Korea.

Methods: This was a cross-sectional study of data from the Korean National Health and Nutrition Examination Survey 2010-2013, with a sample size of 18,563 individuals (6,395 with hearing impairment and 12,168 without hearing impairment), aged $\geq 20$ years.

Results: The female group with hearing impairment tended to have a higher rate of stress (odds ratio [OR], 1.32; 95\% confidence interval [CI], 1.11 to 1.56). The association between hearing impairment and depressive symptoms was higher in elderly males (OR, 1.60; 95\% CI, 1.10 to 2.32), while the association of hearing impairment with suicide ideation was higher in elderly females (OR, 1.32; $95 \%$ CI, 1.00 to 1.75).

Conclusion: Elderly individuals with hearing impairment are easily susceptible to poor mental health status. Early targeted intervention to address mental health problems is recommended for people with hearing impairment.

Keywords: Depression; Hearing; Impairment; Mental Health; Suicide; Stress 


\section{INTRODUCTION}

Hearing impairment has become an important issue in public health worldwide, ${ }^{1)}$ and the prevalence of hearing impairment is growing with the increase of elderly within the population. ${ }^{2)}$ Moreover, the risk factors of hearing impairment such as diabetes, hypertension, smoking, and binge alcohol drinking are common to our modern environment. ${ }^{3,4)}$ Diminished communication, as a result of hearing impairment, can lead to social isolation, cognitive and functional decline, and dementia, decreasing the overall quality of life, which negatively affects mental health. ${ }^{5-7)}$ Several previous studies have reported the association between hearing impairment and mental health, including increasing levels of depression and suicide ideation. ${ }^{8,9)}$ However, there is lack of evidence concerning this relationship from a Korean representative sample, grouped by sex and age. Poor mental health is one of the most important issues in Korea, as Korea is the country with the highest suicide rate, but the second lowest worldwide rate of antidepressant consumption in 2013. ${ }^{10)}$ Recently, the Korean government has made great efforts to create better conditions that may lead to an improvement in mental health status. Understanding the factors related to poor mental health might be helpful in deciding the most effective way to improve mental health in Korea. Therefore, our study aimed to determine the association between hearing impairment and mental health in Korea utilizing data obtained from the Korean National Health and Nutrition Examination Survey (KNHANES) 20102013.

\section{METHODS}

\section{Subjects}

The study was based on data obtained for the KNHANES, performed by the Korean Ministry of Health and Welfare. KNHANES is a nationwide representative study, performed in six phases: phase I (1998), II (2001), III (2005), IV (2007-2009), V (2010-2012), and VI (2013-2014). This survey used a stratified, multistage probability sampling design for the selection of household units. In order to represent the entire Korean adult population, sampling weights were used to account for the complex sampling, which included stratification by district at the first step and stratification by sex and age at the second step. The survey consisted of the health interview survey, the health behavior survey, the nutrition survey, and the health examination survey. All data was obtained through self-administered questionnaires, with interviewers providing assistance to those who were unable to self-administer. Written informed consent to use data for further analyses was provided by all participants who were given the right to refuse to participate in accordance with the National Health Enhancement Act. Cross-sectional analyses were performed on data obtained from 33,552 subjects of the KNHANES V and VI (2010-2013) who participated in the Health Interview Survey and the Health Examination Survey. Of these, a total of 18,563 individuals (8,041 male, 10,522 female), aged $\geq 20$ years, with data from audiometric testing, were included in the final study analyses.

\section{Definition of Hearing Impairment}

Pure-tone audiometric testing was done using a SA 203 audiometer (Entomed, Malomo, Sweden). The test was conducted in a soundproof room located inside a mobile bus. All test processes, including instruction to the subjects, was performed by trained otolaryngologists. Furthermore, the result of air conduction thresholds was recorded using supra-auricular headphones. Automated testing was done through a modified Hughson-Westlake procedure, which used a single, pure tone, lasting 1 to 2 seconds. The threshold of the lowest level was defined when the participants responded to $50 \%$ of the pure tone. The reliability and validity of the automated hearing test was good, as compared to the manual test. ${ }^{11,12)}$ When the subjects heard the tone, they were instructed to push a button. The test frequencies were $0.5,1,2,3$, 4 , and $6 \mathrm{kHz}$. The definition of hearing impairment was adopted from the definition utilized by the World Health Organization (speech frequency pure tone average) which was responding to frequencies $\geq 25$ decibels, using the mean level of frequencies $0.5,1,2$, and $4 \mathrm{kHz}$, in either the right or left ear. ${ }^{13)}$

\section{Definition of Mental Health Status}

To investigate mental health status, we examined levels of stress, presence of depressive symptoms, and response to suicide related statements or questions, adopted from the KNHANES V, such as "Describe the amount of your stress in your daily life": (1) "I feel a lot of stress" or (2) "I feel stress a little," and "Have you had depression symptoms for more than 2 weeks recently?": (1) “yes" or (2) "no." We also asked the question, "Have you had suicidal ideation in the past year?": (1) "yes" or (2) "no." Respondents answered the questions based on memory. Data of unanswered questions were treated as missing values.

\section{Definition of Socioeconomic Variables, Health Risk Behaviors, and Diseases}

Self-administered questionnaires from the health interview survey was used to gather information about socioeconomic factors (age, gender, education level, household monthly income, employed status, marital status), health-related factors (smoking status, alcohol drinking, physical activity, mental health status), diabetes, and hypertension. Education level was classified into 'university or higher,' 'middlehigh school,' and 'elementary school or lower.' The household income variable was categorized into quartiles. Marital status was divided into 'married,' 'separated, and 'never.' Occupation status was divided into 'employed' or 'unemployed,' which included students or homemakers. Smoking status was categorized as 'current smoker' or 'past/nonsmoker,' which included ex-smokers and individuals that had never smoked. 'Current smoker' included those who currently smoke regularly or intermittently. 'High-risk alcohol consumption' was assessed using the question "How often do you binge drink?" and was categorized into two groups according to the frequency of binge drinking. Binge drinking was defined as $\geq 7$ drinks for men and $\geq 5$ drinks for 
women on one occasion. Individuals were classified as 'non-binge drinker' who reported binge drinking less than once per month and as 'binge drinker' who reported binge drinking once or more per month. ${ }^{14,15)}$ Physical inactivity was assessed with items based on the International Physical Activity Questionnaire (IPAQ) short form. ${ }^{16)}$ 'Insufficient physical activity' was classified as none or some reported activity, but not enough to meet the categories 2 (moderate) or 3 (high) of physical activity levels in the IPAQ. Categories 2 (moderate) or 3 (high) of physical activity were included in 'sufficient physical activity' as a reference. More details concerning these criteria are described in IPAQ guidelines. ${ }^{17)}$ Body weight and height were measured to the nearest $0.1 \mathrm{~kg}$ and $0.1 \mathrm{~cm}$, respectively, while participants were wearing light indoor clothes, and without shoes. Body mass index (BMI) was calculated as the ratio of weight in kilograms to squared height in meters $\left(\mathrm{kg} / \mathrm{m}^{2}\right)$. Diabetes mellitus was defined by a fasting plasma glucose level $\geq 126 \mathrm{mg} / \mathrm{dL}$, or the use of anti-diabetic medications. Hypertension was defined by a systolic blood pressure $\geq 140 \mathrm{~mm} \mathrm{Hg}$, a diastolic blood pressure $\geq 90 \mathrm{~mm} \mathrm{Hg}$, or through the use of anti-hypertensive medications.

\section{Statistical Analysis}

In the present study, all sampling and weight variables were stratified, and the IBM SPSS survey procedure ver. 20.0 (IBM Corp., Armonk, NY, USA) was used. Statistical analyses were performed to demonstrate descriptive statistics categorized by the presence of hearing impairment and by mental health. A Student t-test and chi-square test were performed to examine relationships among the multiple variables by presence of hearing impairment. Multiple logistic regression analyses were used to determine the level of association between mental health, and multiple variables, including sex and age. Odds ratios (ORs) were calculated after adjusting for age, sex, marital status, educational level, household income level, occupation, diabetes, hypertension, BMI, smoking, binge alcohol drinking, and physical activity, as these were the variables known to be associated not only with hearing impairment, but also with mental health status, both clinically and statistically. All statistical tests were two-sided and statistical significance was determined at a P-value $<0.05$.

\section{RESULTS}

Basic characteristics are shown in Table 1. Among the 18,563 participants analyzed (6,395 hearing impairment and 12,168 non-hearing impairment), hearing impairment group was older, and demonstrated lower levels of current smokers, binge drinkers, physical activity, monthly household income, and employment. Furthermore, the rates of both diabetes and hypertension were higher in people with hearing impairment. Table 2 presented potential risk factors of mental health status. Perceived stress was found to be higher in females, current smokers, binge alcohol drinkers, individuals with more than university level education, individuals with a low-middle household income, as well as in single, and employed individuals. Conversely, perceived stress was found to be lower in old age, overweight, and individuals displaying sufficient physical activity. Depressive symptoms were higher in old age, females, low and lower-middle household income, separated individuals, as well as within those with diabetes and hypertension. Conversely, depressive symptoms were lower in individuals displaying sufficient physical activity, more than middle school educational level, and those that were employed. Regarding suicide ideation,

Table 1. Basic characteristics of hearing impairment and non-hearing impairment population in males and females

\begin{tabular}{|c|c|c|c|c|c|c|}
\hline \multirow{2}{*}{ Characteristic } & \multicolumn{3}{|c|}{ Male $(n=8,041)$} & \multicolumn{3}{|c|}{ Female $(n=10,522)$} \\
\hline & Hearing impairment & Non-hearing impairment & P-value* & Hearing impairment & Non-hearing impairment & P-value* \\
\hline Total no. & $3,202(39.8)$ & $4,839(60.2)$ & & $3,193(30.4)$ & $7,329(69.7)$ & \\
\hline Age (y) & $59.7 \pm 0.4$ & $42.6 \pm 0.3$ & $<0.001$ & $64.0 \pm 0.4$ & $45.0 \pm 0.2$ & $<0.001$ \\
\hline Body mass index $\left(\mathrm{kg} / \mathrm{m}^{2}\right)$ & $23.8 \pm 0.07$ & $24.4 \pm 0.06$ & $<0.001$ & $24.0 \pm 0.08$ & $23.4 \pm 0.06$ & $<0.001$ \\
\hline Current smoker (\%) & $39.5(1.2)$ & $47.5(0.9)$ & $<0.001$ & $5.5 \pm 0.6$ & $6.5 \pm 0.4$ & 0.16 \\
\hline Alcohol binge drinker (\%) & $41.4(1.2)$ & $60.2(0.9)$ & $<0.001$ & $6.4 \pm 0.8$ & $16.6 \pm 0.7$ & $<0.001$ \\
\hline Sufficient physical activity (\%) & $49.2(1.2)$ & $49.8(0.9)$ & 0.67 & $36.5 \pm 1.2$ & $43.7 \pm 0.7$ & $<0.001$ \\
\hline Education level (\%) & & & $<0.001$ & & & $<0.001$ \\
\hline$\leq$ Elementary school & $34.8(0.9)$ & $8.9(0.4)$ & & $67.4(0.8)$ & $20.6(0.5)$ & \\
\hline Middle-high school & $48.3(0.9)$ & $47.9(0.7)$ & & $27.3(0.8)$ & $49.3(0.6)$ & \\
\hline$\geq$ University & $16.9(0.7)$ & $43.2(0.7)$ & & $5.3(0.4)$ & $30.1(0.5)$ & \\
\hline Household income (10 ${ }^{4}$ Korean won/mo) & $119.0 \pm 4.9$ & $154.2 \pm 7.2$ & $<0.001$ & $93.2 \pm 3.6$ & $135.0 \pm 3.4$ & $<0.001$ \\
\hline Marital status (\%) & & & $<0.001$ & & & $<0.001$ \\
\hline Married & $88.7(0.6)$ & $80.2(0.6)$ & & $59.8(0.9)$ & $77.7(0.5)$ & \\
\hline Separated & $8.9(0.5)$ & $3.8(0.3)$ & & $38.2(0.9)$ & $12.5(0.4)$ & \\
\hline Single & $2.4(0.3)$ & $16.0(0.5)$ & & $1.9(0.2)$ & $9.8(0.3)$ & \\
\hline Occupation: yes (\%) & $67.9(1.1)$ & $82.7(0.7)$ & $<0.001$ & $38.5 \pm 1.2$ & $54.1 \pm 0.8$ & $<0.001$ \\
\hline Diabetes (\%) & $17.7(0.9)$ & $9.4(0.5)$ & $<0.001$ & $17.5 \pm 0.9$ & $6.5 \pm 0.4$ & $<0.001$ \\
\hline Hypertension (\%) & $46.0(1.1)$ & $29.9(0.8)$ & $<0.001$ & $51.4 \pm 1.3$ & $20.6 \pm 0.6$ & $<0.001$ \\
\hline
\end{tabular}

Values are presented as number (\%) or mean \pm standard deviation.

*By Student t-test or chi-square test. 
Table 2. Potential risk factors of mental health status using logistic regression analysis

\begin{tabular}{|c|c|c|c|}
\hline Variable & Perceived stress & Depressive symptom & Suicide ideation \\
\hline \multicolumn{4}{|l|}{ Age (y) } \\
\hline $20-39$ & 1 & 1 & 1 \\
\hline $40-59$ & $0.66(0.60-0.73)$ & $1.23(1.07-1.41)$ & $0.93(0.80-1.08)$ \\
\hline$\geq 60$ & $0.54(0.49-0.60)$ & $1.52(1.32-1.75)$ & $1.52(1.31-1.76)$ \\
\hline \multicolumn{4}{|l|}{ Sex } \\
\hline Male & 1 & 1 & 1 \\
\hline Female & $1.34(1.22-1.46)$ & $2.11(1.88-2.36)$ & $1.96(1.75-2.20)$ \\
\hline \multicolumn{4}{|l|}{ Body mass index $\left(\mathrm{kg} / \mathrm{m}^{2}\right)$} \\
\hline$<23$ & 1 & 1 & 1 \\
\hline $23-25$ & $0.89(0.80-0.99)$ & $0.96(0.84-1.09)$ & $0.93(0.81-1.06)$ \\
\hline$\geq 25$ & $1.06(0.96-1.16)$ & $0.94(0.84-1.05)$ & $1.00(0.89-1.19)$ \\
\hline \multicolumn{4}{|l|}{ Smoking } \\
\hline No/past & 1 & 1 & 1 \\
\hline Current & $1.33(1.19-1.48)$ & $0.98(0.86-1.11)$ & $1.09(0.96-1.23)$ \\
\hline \multicolumn{4}{|l|}{ Alcohol binge drinker } \\
\hline No & 1 & 1 & 1 \\
\hline Yes & $1.29(1.18-1.42)$ & $0.89(0.77-1.02)$ & $0.86(0.75-0.98)$ \\
\hline \multicolumn{4}{|l|}{ Sufficient physical activity } \\
\hline No & 1 & 1 & 1 \\
\hline Yes & $0.88(0.81-0.96)$ & $0.78(0.70-0.86)$ & $0.88(0.79-0.98)$ \\
\hline \multicolumn{4}{|l|}{ Education level } \\
\hline$\leq$ Elementary school & 1 & 1 & 1 \\
\hline Middle-high school & $0.92(0.83-1.01)$ & $0.62(0.55-0.70)$ & $0.52(0.46-0.58)$ \\
\hline ZUniversity & $1.17(1.07-1.29)$ & $0.39(0.33-0.45)$ & $0.37(0.32-0.43)$ \\
\hline \multicolumn{4}{|c|}{ Household income $\left(10^{4}\right.$ Korean won/mo) } \\
\hline Q1 $(<50)$ & 1 & 1 & 1 \\
\hline Q2 $(\geq 50<91)$ & $1.19(1.06-1.33)$ & $2.10(1.81-2.44)$ & $2.70(2.29-3.19)$ \\
\hline Q3 $(\geq 91<142)$ & $1.03(0.92-1.15)$ & $1.30(1.11-1.52)$ & $1.46(1.24-1.72)$ \\
\hline Q4 ( $\geq 142)$ & $0.96(0.86-1.08)$ & $1.00(0.85-1.18)$ & $1.23(1.04-1.46)$ \\
\hline \multicolumn{4}{|l|}{ Marital status } \\
\hline Married & 1 & 1 & 1 \\
\hline Separated & $1.10(0.97-1.24)$ & $2.05(1.79-2.33)$ & $2.35(2.04-2.70)$ \\
\hline Single & $1.48(1.30-1.68)$ & $0.93(0.78-1.11)$ & $1.29(1.08-1.54)$ \\
\hline \multicolumn{4}{|l|}{ Occupation } \\
\hline No & 1 & 1 & 1 \\
\hline Yes & $1.20(1.10-1.30)$ & $0.61(0.54-0.67)$ & $0.61(0.55-0.68)$ \\
\hline \multicolumn{4}{|l|}{ Diabetes } \\
\hline No & 1 & 1 & 1 \\
\hline Yes & $0.88(0.77-1.01)$ & $1.36(1.15-1.60)$ & $1.37(1.16-1.62)$ \\
\hline \multicolumn{4}{|l|}{ Hypertension } \\
\hline No & 1 & 1 & 1 \\
\hline Yes & $0.95(0.87-1.03)$ & $1.19(1.07-1.33)$ & $1.33(1.19-1.50)$ \\
\hline
\end{tabular}

Values are presented as odds ratio (95 confidence interval).

similar associations with depressive symptoms were observed except a low prevalence in binge alcohol drinkers. Table 3 provides OR and $95 \%$ confidence interval (CI) for hearing impairment according to the mental health status by sex and age. In the oldest male group $(\geq 60$ years), hearing impairment was associated with depressive symptoms and suicide ideation (OR, 1.55; 95\% CI, 1.08 to 2.21; OR, 1.53; 95\% CI, 1.04 to 2.26 , respectively). In the female group, hearing impairment was associated with perceived stress (OR, 1.30; 95\% CI, 1.09 to 1.54 ); however, in subgroup analyses by age, no significant associations were observed. In the oldest female group, hearing impairment was associated with depressive symptom and suicide ideation, however the as- sociation with depressive symptom disappeared after adjustment in model 3 (OR, 1.25; 95\% CI, 0.93 to 1.67; OR, 1.37; 95\% CI, 1.04 to 1.80 , respectively).

\section{DISCUSSION}

This study indicated that the female group with hearing impairment tended to have higher rates of stress. In addition, an association of hearing impairment with depressive symptoms was observed. Furthermore, suicide ideation was found to be elevated in the old aged group and stronger in males than in females. These results are consis- 
Table 3. Odds ratios of mental health status according to hearing impairment by sex and age group

\begin{tabular}{|c|c|c|c|c|}
\hline Variable & Category & Perceived stress & Depressive symptom & Suicide ideation \\
\hline \multicolumn{5}{|l|}{ Male } \\
\hline \multirow[t]{3}{*}{ Total } & Model 1 & $1.00(0.84-1.17)$ & $1.10(0.87-1.39)$ & $1.20(0.96-1.50)$ \\
\hline & Model 2 & $1.07(0.90-1.26)$ & $0.97(0.76-1.24)$ & $1.05(0.82-1.35)$ \\
\hline & Model 3 & $1.11(0.92-1.34)$ & $0.94(0.74-1.20)$ & $1.01(0.77-1.32)$ \\
\hline \multirow{3}{*}{$20-39$ y } & Model 1 & $1.02(0.60-1.72)$ & $1.55(0.67-3.59)$ & $1.16(0.50-2.68)$ \\
\hline & Model 2 & $1.03(0.60-1.75)$ & $1.52(0.65-3.36)$ & $1.09(0.47-2.53)$ \\
\hline & Model 3 & $1.09(0.59-2.04)$ & $1.37(0.54-3.46)$ & $1.32(0.50-3.52)$ \\
\hline \multirow{3}{*}{$40-59$ y } & Model 1 & $1.16(0.93-1.45)$ & $0.86(0.62-1.20)$ & $1.08(0.79-1.49)$ \\
\hline & Model 2 & $1.21(0.96-1.51)$ & $0.81(0.58-1.14)$ & $1.02(0.73-1.44)$ \\
\hline & Model 3 & $1.22(0.97-1.55)$ & $0.75(0.53-1.07)$ & $0.86(0.59-1.25)$ \\
\hline \multirow[t]{3}{*}{$\geq 60 y$} & Model 1 & $0.97(0.72-1.29)$ & $1.72(1.22-2.44)$ & $1.51(1.06-2.15)$ \\
\hline & Model 2 & $0.93(0.69-1.26)$ & $1.62(1.14-2.31)$ & $1.42(0.98-2.06)$ \\
\hline & Model 3 & $0.90(0.65-1.25)$ & $1.60(1.10-2.32)$ & $1.43(0.96-2.14)$ \\
\hline \multicolumn{5}{|l|}{ Female } \\
\hline \multirow[t]{3}{*}{ Total } & Model 1 & $1.46(1.27-1.67)$ & $1.29(1.09-1.51)$ & $1.61(1.37-1.88)$ \\
\hline & Model 2 & $1.32(1.15-1.52)$ & $1.16(0.98-1.37)$ & $1.30(1.11-1.53)$ \\
\hline & Model 3 & $1.32(1.11-1.56)$ & $1.15(0.93-1.42)$ & $1.36(1.11-1.67)$ \\
\hline \multirow[t]{3}{*}{$20-39$ y } & Model 1 & $1.15(0.69-1.92)$ & $0.72(0.36-1.43)$ & $1.16(0.65-2.07)$ \\
\hline & Model 2 & $1.10(0.64-1.90)$ & $0.74(0.38-1.45)$ & $0.98(0.52-1.85)$ \\
\hline & Model 3 & $1.28(0.67-2.45)$ & $0.81(0.35-1.87)$ & $1.12(0.52-2.41)$ \\
\hline \multirow[t]{3}{*}{$40-59$ y } & Model 1 & $1.24(1.00-1.54)$ & $1.32(1.01-1.74)$ & 1.38 (1.03-1.84) \\
\hline & Model 2 & $1.23(0.99-1.53)$ & $1.22(0.91-1.62)$ & $1.27(0.95-1.71)$ \\
\hline & Model 3 & $1.18(0.91-1.53)$ & $1.25(0.89-1.75)$ & $1.27(0.91-1.76)$ \\
\hline \multirow[t]{3}{*}{$\geq 60 y$} & Model 1 & $1.34(1.10-1.66)$ & $1.40(1.13-1.72)$ & $1.37(1.11-1.70)$ \\
\hline & Model 2 & $1.26(1.02-1.55)$ & $1.37(1.10-1.69)$ & $1.27(1.03-1.58)$ \\
\hline & Model 3 & $1.24(0.95-1.61)$ & $1.32(0.97-1.80)$ & $1.32(1.00-1.75)$ \\
\hline
\end{tabular}

Values are presented as odds ratio (95 confidence interval). Model 1: adjusted with age; model 2: adjusted with age, marital status, educational level, household income, and occupation; model 3: adjusted with age, marital status, educational level, household income, occupation, diabetes, hypertension, body mass index, smoking, alcohol binge drinker, and physical activity.

tent with previous studies. For instance, a study conducted by Kobayashi et al. ${ }^{18)}$ found a high association between Japanese individuals with hearing impairment and psychological distress in mental health (OR, 4.889; 95\% CI, 4.267 to 5.601). Moreover, a separate study conducted by Armstrong et al. ${ }^{19)}$ reported that individuals with hearing impairment displayed higher rates of depression (hearing impairment vs. non-hearing impairment: $19.3 \%$ vs. $14.6 \%$ in the CESD-5 [Center for Epidemiologic Studies-Depression 5] scale, $14.9 \%$ vs. $9.1 \%$ in the PHQ-9 [Patient Health Questionnaire-9] scale). Additionally, Gomaa et al. ${ }^{20)}$ 's study showed that depression was more related to old age in males than in females, and that stress was more closely related with middle age in females than in males. Furthermore, a study conducted by Kim et al. ${ }^{21)}$ showed that elderly with sensory impairment had 1.601.76 fold higher risk for suicide ideation. Finally, Turner et al. ${ }^{22)}$ reported a significant gap between a hearing impairment group and a control group regarding depression and suicide ideation through a literature review.

The mechanism of the association between hearing impairment and poor mental health status has yet to be confirmed. There are however, several theories. First, disabled people tend to lack recognition of their mental problems, when compared to individuals without hearing impairment, so they do not recognize the need for treatment. Second, the socioeconomic environment of discrimination due to, or stig- ma towards, disability leads to depression. Third, people with hearing impairment have difficulties in accessing medical facilities. Therefore, proper diagnosis and management is difficult to provide. Finally, health professionals experience difficulties in communication with individuals that exhibit hearing impairment, so health professionals could overlook or misdiagnose a condition. ${ }^{18,23)}$

Multivariate trials have been conducted to improve mental health in people with hearing impairment; however, more effort is needed to find an effective way to resolve the problem. Boi et al. ${ }^{24)}$ 's study showed that the use of a hearing aid improved depressive symptoms in elderly patients. In contrast, Dawes et al. ${ }^{25)}$ 's study reported no evidence of improved mental health or social isolation after using a hearing aid in people with hearing impairment. Evidence provided by Chen et al. ${ }^{26)}$ 's study suggest that depressive thoughts and feelings in people with hearing impairment have decreased after the recovery of hearing impairment (OR, 0.14 ; 95\% CI, 0.08 to 0.27 ). In the UK, as part of the government's efforts to respond to the needs of the deaf, the primary health care service has assumed an important role in breaking the physical and economical obstacles to treatment through increasing accessibility to health care. ${ }^{27)}$

Korea has the highest rate of suicide in the elderly, among Organization for Economic Cooperation and Development countries. ${ }^{10)}$ From a report by the Ministry of Health and Welfare ${ }^{28)}$ in Korea, the depression 
rate of the elderly population in Korea has increased 1.7 times over the past 5 years. Moreover, $11.2 \%$ of elderly in Korea have experienced suicidal ideation, mainly caused by health problems. ${ }^{29)}$ Furthermore, some elderly individuals with hearing impairment might not be aware of their mental problems; hence, the prevalence of mental illness in the elderly could be underestimated. Therefore, not only treatment for hearing impairment, but also early screening for mental health would be an initial step to improve the mental health status in this population. Additionally, further efforts to break down the barriers between individuals with hearing impairment and medical professionals are absolutely necessary. ${ }^{30}$

There are several limitations in our study. First, the cross-sectional nature of the survey precluded identification of causality. Second, as the people who were admitted to a hospital or nursing home were not included in the KNHANES, and as the severity of mental illness might be underestimated, it is possible that an overrepresentation of people with relatively mild hearing impairment or more severe mental health issues was included in the analysis. Third, the hearing test was conducted once in each participant. Thus, temporary hearing impairment was not differentiated in our study. Forth, our study used self-administered questionnaires for perceived stress, depressive symptoms, and suicide ideation, which may be subject to recall bias or concealment. Finally, there could be many hidden confounding factors that we could not consider. Despite these limitations, a major strength of this study is that it is based on a nationally representative population, with sampling weights that were applied to all analyses to maintain the level of representation of Korean adults in general.

In conclusion, the current study demonstrates that elderly with hearing impairment are easily susceptible to mental illness. Early intervention, including active screening and providing proper care, are recommended for resolving mental health problems in people with hearing impairment.

\section{CONFLICT OF INTEREST}

No potential conflict of interest relevant to this article was reported.

\section{REFERENCES}

1. Olusanya BO, Neumann KJ, Saunders JE. The global burden of disabling hearing impairment: a call to action. Bull World Health Organ 2014;92:367-73.

2. Jun HJ, Hwang SY, Lee SH, Lee JE, Song JJ, Chae S. The prevalence of hearing loss in South Korea: data from a population-based study. Laryngoscope 2015;125:690-4.

3. Lee JS, Choi HG, Jang JH, Sim S, Hong SK, Lee HJ, et al. Analysis of predisposing factors for hearing loss in adults. J Korean Med Sci 2015;30:1175-82.

4. Hong JW, Jeon JH, Ku CR, Noh JH, Yoo HJ, Kim DJ. The prevalence and factors associated with hearing impairment in the Korean adults: the 2010-2012 Korea National Health and Nutrition Examination Survey (observational study). Medicine (Baltimore) 2015;94:e611.

5. Weinstein BE, Ventry IM. Hearing impairment and social isolation in the elderly. J Speech Hear Res 1982;25:593-9.

6. Peracino A. Hearing loss and dementia in the aging population. Audiol Neurootol 2014;19 Suppl 1:6-9.

7. Chia EM, Wang JJ, Rochtchina E, Cumming RR, Newall P, Mitchell P. Hearing impairment and health-related quality of life: the Blue Mountains Hearing Study. Ear Hear 2007;28:187-95.

8. Gopinath B, Wang JJ, Schneider J, Burlutsky G, Snowdon J, McMahon $\mathrm{CM}$, et al. Depressive symptoms in older adults with hearing impairments: the Blue Mountains Study. J Am Geriatr Soc 2009;57:1306-8.

9. Qi B, Li X, Gao W, Liu B. The analysis of correlative factors on mental health of post-linguistic hearing loss adults. Lin Chung Er Bi Yan Hou Tou Jing Wai Ke Za Zhi 2015;29:1598-602.

10. Organization for Economic Cooperation and Development. Health at a glance 2015: OECD indicators. Paris: Organization for Economic Cooperation and Development Publishing; 2015 [cited 2016 May 11]. Available from: http://www.keepeek.com/Digital-Asset-Management/oecd/social-issues-migration-health/health-at-a-glance-2015_ health_glance-2015-en\#page56.

11. Swanepoel de W, Mngemane S, Molemong S, Mkwanazi H, Tutshini S. Hearing assessment-reliability, accuracy, and efficiency of automated audiometry. Telemed J E Health 2010;16:557-63.

12. Mahomed F, Swanepoel de W, Eikelboom RH, Soer M. Validity of automated threshold audiometry: a systematic review and meta-analysis. Ear Hear 2013;34:745-52.

13. World Health Organization. Prevention of blindness and deafness (PBD) program: prevention of deafness and hearing impaired grades of hearing impairment [Internet]. Geneva: World Health Organization; 2010 [cited 2016 Apr 20]. Available from: http://www.who.int/pbd/ deafness/hearing_impairment_grades/en/index.html.

14. LaBrie JW, Pedersen ER, Tawalbeh S. Classifying risky-drinking college students: another look at the two-week drinker-type categorization. J Stud Alcohol Drugs 2007;68:86-90.

15. Jeon, GS, Lee HY. Associated factors of binge drinking and problem drinking among Korean men and women. Korean J Health Educ Promot 2010;27:91-103.

16. International Physical Activity Questionnaire. Guidelines for data processing and analysis of the International Physical Activity Questionnaire (IPAQ): short and long forms [Internet]. [place unknown]: IPAQ Research Committee; 2005 [cited 2016 Apr 20]. Available from: https:// www.google.co.kr/url?sa=t\&rct=j\&q=\&esrc=s\&source=web\&cd=2\&ve $\mathrm{d}=0$ ahUKEwiny9W2lbzMAhV15aYKHVC-CjoQFggnMAE\&url=https\% 3A\%2F\%2Fwww.researchgate.net\%2Ffile.PostFileLoader.html\%3Fid\% 3D56f92d66615e27d49a658031\%26assetKey\%3DAS\%253A344600888 791041\%25401459170662924\&usg=AFQjCNFu86dTe_OuPWOpuYIPhGnZbyAhw\&sig2=m82M-YoYliqzXP4AJpB2_A\&bvm=bv. 121070826,d.dGY.

17. Pate RR, Pratt M, Blair SN, Haskell WL, Macera CA, Bouchard C, et al. Physical activity and public health: a recommendation from the Centers for Disease Control and Prevention and the American College of Sports Medicine. JAMA 1995;273:402-7.

18. Kobayashi Y, Tamiya N, Moriyama Y, Nishi A. Triple difficulties in Japanese women with hearing loss: marriage, smoking, and mental health issues. PLoS One 2015;10:e0116648. 
19. Armstrong TW, Surya S, Elliott TR, Brossart DF, Burdine JN. Depression and health-related quality of life among persons with sensory disabilities in a health professional shortage area. Rehabil Psychol 2016;61:240-50.

20. Gomaa MA, Elmagd MH, Elbadry MM, Kader RM. Depression, Anxiety and Stress Scale in patients with tinnitus and hearing loss. Eur Arch Otorhinolaryngol 2014;271:2177-84.

21. Kim Y, Kwak Y, Kim JS. The association between suicide ideation and sensory impairment among elderly Koreans. Aging Ment Health 2015;19:658-65.

22. Turner O, Windfuhr K, Kapur N. Suicide in deaf populations: a literature review. Ann Gen Psychiatry 2007;6:26.

23. Okoro CA, Dhingra SS, Li C. A triple play: psychological distress, physical comorbidities, and access and use of health services among U.S. adults with disabilities. J Health Care Poor Underserved 2014;25:81436.

24. Boi R, Racca L, Cavallero A, Carpaneto V, Racca M, Dall' Acqua F, et al. Hearing loss and depressive symptoms in elderly patients. Geriatr Gerontol Int 2012;12:440-5.
25. Dawes P, Cruickshanks KJ, Fischer ME, Klein BE, Klein R, Nondahl DM. Hearing-aid use and long-term health outcomes: hearing handicap, mental health, social engagement, cognitive function, physical health, and mortality. Int J Audiol 2015;54:838-44.

26. Chen J, Liang J, Ou J, Cai W. Mental health in adults with sudden sensorineural hearing loss: an assessment of depressive symptoms and its correlates. J Psychosom Res 2013;75:72-4.

27. Levine J. Primary care for deaf people with mental health problems. Br J Nurs 2014;23:459-63.

28. Ministry of Health and Welfare. Elderly people in depression increased by 1.7 times over the past five years [Internet]. Sejong: Ministry of Health and Welfare; 2011 [cited 2016 Apr 20]. Available from: https:// www.mohw.go.kr/front_new/al/sal0301vw.jsp?PAR_MENU_ID= 04\&MENU_ID=0403\&CONT_SEQ=249839\&page=9.

29. Park JI, Yang JC, Han C, Park TW, Chung SK. Suicidal ideation among Korean elderly: risk factors and population attributable fractions. Psychiatry 2016;79:262-81.

30. Noble W. Preventing the psychosocial risks of hearing loss. Aust Fam Physician 2009;38:591-3. 